\title{
Control System for the LLNL Kicker Pulse Generator
}

J. A. Watson, R. M. Anaya, E. G. Cook, B. S. Lee, S. A. Hawkins

This article was submitted to 2002 International Power Modulator Conference, Hollywood, CA., June 30-July 3, 2002

\section{June 18, 2002}

Lawrence

Livermore

National

Laboratory

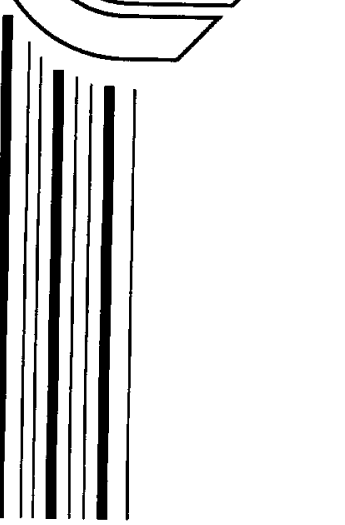




\section{DISCLAIMER}

This document was prepared as an account of work sponsored by an agency of the United States Government. Neither the United States Government nor the University of California nor any of their employees, makes any warranty, express or implied, or assumes any legal liability or responsibility for the accuracy, completeness, or usefulness of any information, apparatus, product, or process disclosed, or represents that its use would not infringe privately owned rights. Reference herein to any specific commercial product, process, or service by trade name, trademark, manufacturer, or otherwise, does not necessarily constitute or imply its endorsement, recommendation, or favoring by the United States Government or the University of California. The views and opinions of authors expressed herein do not necessarily state or reflect those of the United States Government or the University of California, and shall not be used for advertising or product endorsement purposes.

This is a preprint of a paper intended for publication in a journal or proceedings. Since changes may be made before publication, this preprint is made available with the understanding that it will not be cited or reproduced without the permission of the author.

This work was performed under the auspices of the United States Department of Energy by the University of California, Lawrence Livermore National Laboratory under contract No. W-7405-Eng-48.

This report has been reproduced directly from the best available copy.

Available electronically at http://www.doc.gov/bridge

Available for a processing fee to U.S. Department of Energy

And its contractors in paper from

U.S. Department of Energy

Office of Scientific and Technical Information

P.O. Box 62

Oak Ridge, TN 37831-0062

Telephone: (865) 576-8401

Facsimile: (865) 576-5728

E-mail: reports@adonis.osti.gov

Available for the sale to the public from

U.S. Department of Commerce

National Technical Information Service

5285 Port Royal Road

Springfield, VA 22161

Telephone: (800) 553-6847

Facsimile: (703) 605-6900

E-mail: orders@ntis.fedworld.gov

Online ordering: http://www.ntis.gov/ordering.htm

\section{OR}

Lawrence Livermore National Laboratory

Technical Information Department's Digital Library

http://www.llnl.gov/tid/Library.html 


\title{
CONTROL SYSTEM FOR THE LLNL KICKER PULSE GENERATOR
}

\author{
J.A. Watson, R. M. Anaya, E.G. Cook, B.S. Lee, S.A. Hawkins \\ Lawrence Livermore National Laboratory
}

\section{Abstract}

A solid-state high voltage pulse generator with multipulse burst capability, very fast rise and fall times, pulse width agility, and amplitude modulation capability for use with high speed electron beam kickers has been designed and tested at LLNL. A control system calculates a desired waveform to be applied to the kicker based on measured electron beam displacement then adjusts the pulse generators to provide the desired waveform. This paper presents the design of the control system and measured performance data from operation on the ETA-II accelerator at LLNL.

\section{Introduction}

High-speed beam kickers are used to provide precision beam manipulation for high current electron beams. This technology has been demonstrated on the ETA-II accelerator at LLNL, and will be used on the $2^{\text {nd }}$ axis of the DARHT accelerator at LANL. A detailed treatment of the kicker can be found in [1]. The pulse generators used to drive the kicker employ inductive adder topology, and include amplitude modulation capability ${ }^{[2,3]}$ to compensate for transverse e-beam motion at the kicker input as well as the dynamic response and beam-induced steering effects associated with the kicker structure.

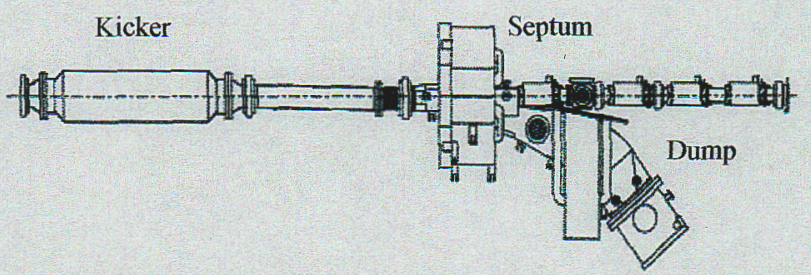

Figure 1 DARHT II kicker and associated transport elements

\section{The Pulse Generator}

The pulse generator is a linear inductive adder, essentially a stack of transformers with the secondaries connected in series. The primary and secondary winding of each stage consists of a single turn. MOSFETS are used to switch energy stored in a capacitor into the primary of each transformer. As illustrated in figure 2, the conduction interval of each stage is controlled by the width of the pulse on the drive circuit of the device, allowing for variable pulse width and burst capability ${ }^{[2]}$. Amplitude modulation is accomplished by controlling individual stages in the adder structure. Some of the boards are charged to one half or one fourth of the nominal charge voltage to achieve fine voltage control. The system is essentially a high voltage, ultra-high speed D/A converter.

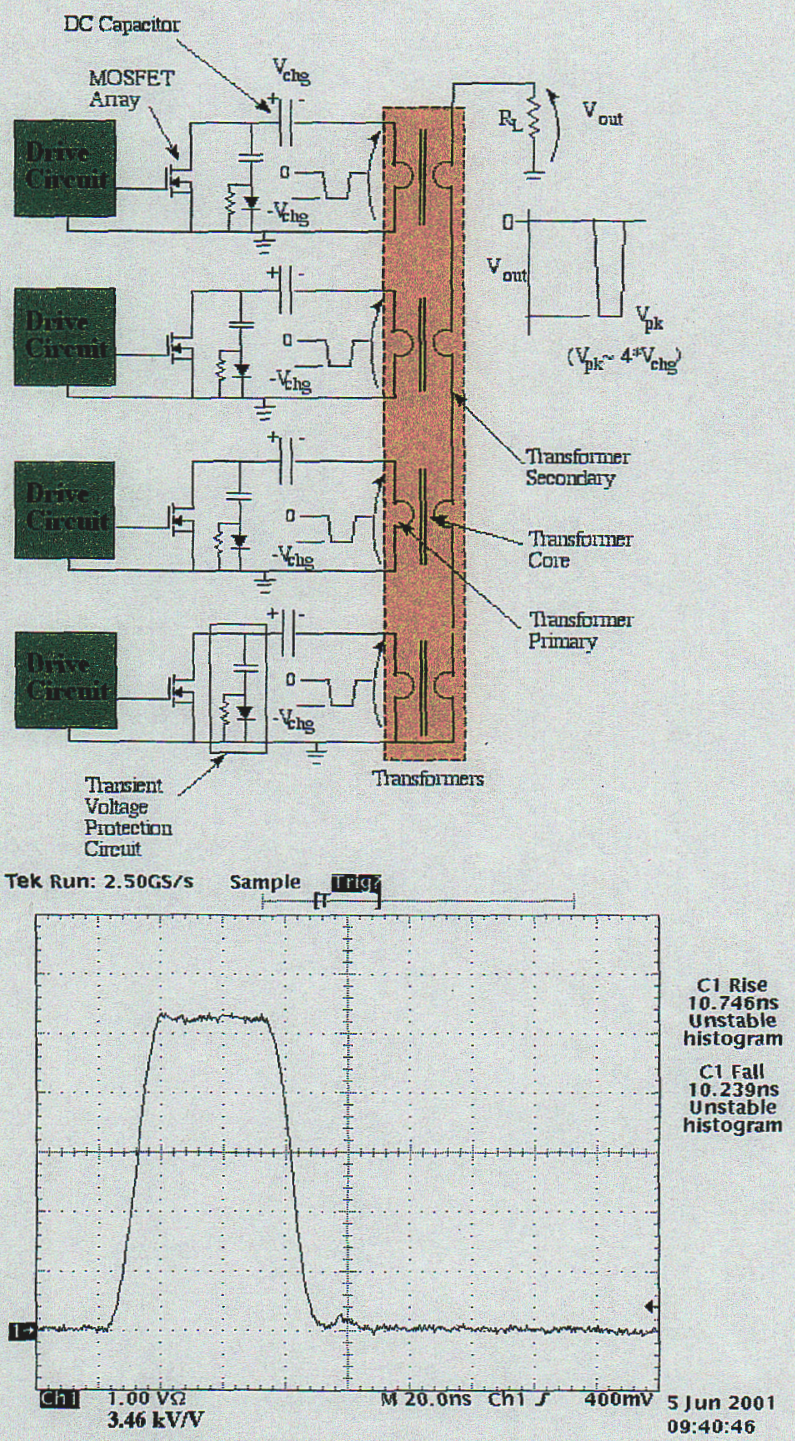

Figure 2 Solid-state modulator block diagram and typical output waveform into $50 \mathrm{ohms}$

This work was performed under the auspices of the U.S. Department of Energy by the University of California Lawrence Livermore National Laboratory under Contract No. W-7405-Eng-48 
While the turn-on time of the adder assembly is extremely fast (approaching $20 \mathrm{kV}$ in $10 \mathrm{nS}$ ), articulation of the amplitude is much more difficult as each modulation stage must switch the full output current of nearly $400 \mathrm{~A}$. We have achieved slew rates of over $50,000 \mathrm{~V} / \mu \mathrm{Sec}$ (linear ramp) using this approach.

\section{Control System}

The control system used to determine the desired pulser output voltage to be applied to the kicker utilizes a feedforward design whereby the calculated voltage is based on information from current and past iterations. The beam is not actively controlled as it passes through the kicker; rather the voltage applied to the kicker is calculated based on the measured position of the beam on the previous pulse. There are two components to the control system, one that calculates the desired voltage to be applied to the kicker and the second to accurately control the output of the pulsers. The first component, referred to as the beam control algorithm, calculates the desired voltage based on measured electron beam position. The second component, the pulser control algorithm, sets the actual output voltage of the pulsers. The control system uses National Instrument's LabView development environment running on a WINNT ${ }^{\circledR} \mathrm{PC}$ platform. Acquisition of beam position data is accomplished with a GPIB interface to a Tektronix ${ }^{\circledR}$ TDS 600 series oscilloscope sampling at $1 \mathrm{GHz}$. Alternatively, the system can interface to other systems (including the data acquisition system used at the DARHT II facility at LANL) through a simple file sharing interface. Control of individual stages of the pulsers is provided by a Tektronix ${ }^{\circledast}$ AWG520 10 bit Digital Pattern Generator, also sampling at $1 \mathrm{GHz}$. Additionally, the control system passes miscellaneous control and status signals through a discrete input/output interface to a PLC.

\subsection{Beam Control Algorithm}

The beam control algorithm calculates the desired voltage to be applied to the kicker. A detailed treatment can be found in [1] and [4]. If we assume negligible beaminduced steering effects, we have a solution to the differential-integral equation of the kicker as a function of time

$$
x(z=l, t)=\frac{c^{2}}{4 V_{0} l} \int_{t-2 l / c}^{t} V_{p}\left(t^{\prime}\right)\left(t-t^{\prime}\right) d t^{\prime}
$$

where $V_{p}(t)$ is the applied voltage and $c$ is the speed of light. The beam control algorithm compares measured electron beam position to a desired setpoint and calculates a desired waveform to be applied to the kicker using an $8^{\text {th }}$ order polynomial approximation of (1). The control system is iterative and adaptive, and can correct for effects that are deterministic but not correctly estimated by (1), including beam-induced steering and the impedance characteristics of the kicker structure. On each successful iteration, the beam control algorithm feeds a desired waveform to the pulser control algorithm.

\subsection{Pulser Control Algorithm}

This algorithm forces the actual output of the pulsers (measured at the kicker) to match the desired waveform from the beam control algorithm. The conduction interval of the MOSFET switches used in the pulsers is not linearly related to the width of the gate drive pulse for narrow pulses due to characteristics inherent with the devices. Figure 3 shows the relationship between output pulsewidth to input (gate) pulsewidth for a typical stage. For pulses under about $18 \mathrm{nS}$, the devices do not turn on at all. Accurate control of pulsewidth from $20-120 \mathrm{nS}$ was a design requirement for the DARHT II application. For pulses between $20-40 \mathrm{nS}$, the peak amplitude of the desired output pulse is set by turning on additional stages in the adder with the same pulsewidth as the main portion of the pulser.

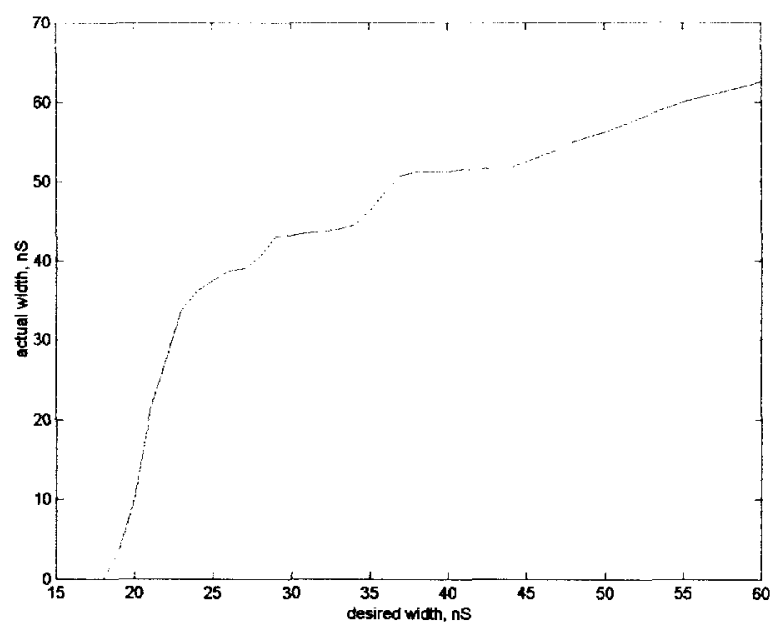

Figure 3 MOSFET switch output pulsewidth versus desired width

Lookup tables are used to match the pulser output pulsewidth to the desired pulsewidth for the narrower pulses. Proportional-integral feedback with an adaptive element is used to match the peak amplitude of the pulsers to the desired voltage. Additionally, a derivative feedforward term is used to help compensate for fastchanging levels in the desired waveform. For pulses between $41-120 \mathrm{nS}$, the pulser control algorithm matches the output pulse amplitude on a point-by-point basis (at InS per point) with the desired voltage.

\section{Performance}

For the ETA-II experiments, two-thirds of the pulser stages were removed to scale for lower energy $(6 \mathrm{MeV}$ vs. $20 \mathrm{MeV}$ on DARHT II). Preliminary testing of the pulsers and control system was performed with the pulsers connected to resistive loads. Figure 4 shows performance of the control system for a series of four different width pulses and an arbitrary amplitude component. This measured performance data was the result of five algorithm iterations. Note that the pulser control algorithm can run independently of the accelerator. The 
iteration speed is limited by the pulse generator's DC charging supply to approximately $0.2 \mathrm{~Hz}$.

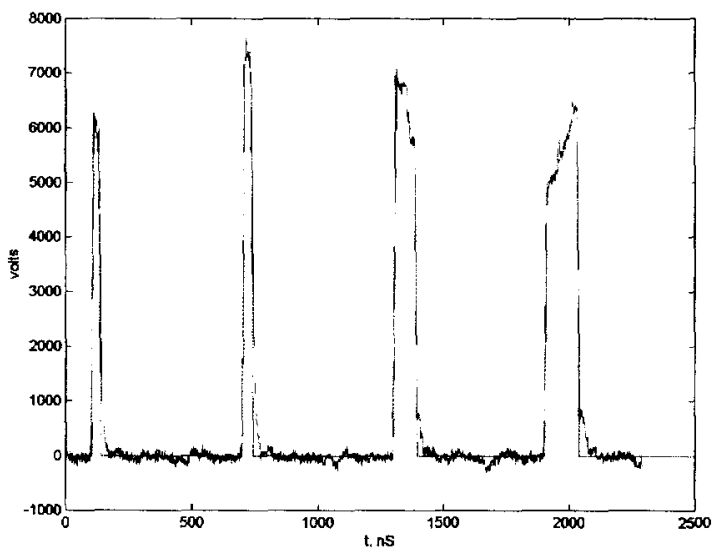

Figure 4 Desired and measured pulser voltage for a 4-pulse burst

Convergence of the beam control algorithm is dependent on several factors, including repeatability of the accelerator and the amplitude of transverse motion on the incoming beam. On the ETA-II accelerator, only a single section of beam can be kicked due to the narrow beam width $(50 \mathrm{nS}$ vs. $2 \mu \mathrm{S}$ for DARHT II). In normal operation, the kicker is operated with a dipole surrounding the structure to steer the beam off center and ultimately into the dump. Energizing the kicker overcomes the dipole field and the kicked portion of the beam is transported straight ahead. To transport the full beam on ETA-II, this dipole was simply turned off. In addition, the incoming beam was transported through an aperture to lower current from $2 \mathrm{kA}$ to approximately $200 \mathrm{~A}$, to reduce space charge effects of the lower energy ETA-II beam. Figure 4 shows measured beam current on ETA-II after the kicker for a full and 20nS-wide kicked beam. To evaluate the amplitude modulation capability, a $4 \ln S$ wide pulse was applied to the kicker. Figure 6 shows unkicked and kicked beam position measured downstream of the kicker. The system converged to $\pm 1 \mathrm{~mm}$ of the desired beam position setpoint in three iterations (three beam shots). Note that with the exception of the head and tail of the beam, the control system corrected for transverse motion (intentionally introduced corkscrew motion) of the incoming beam.

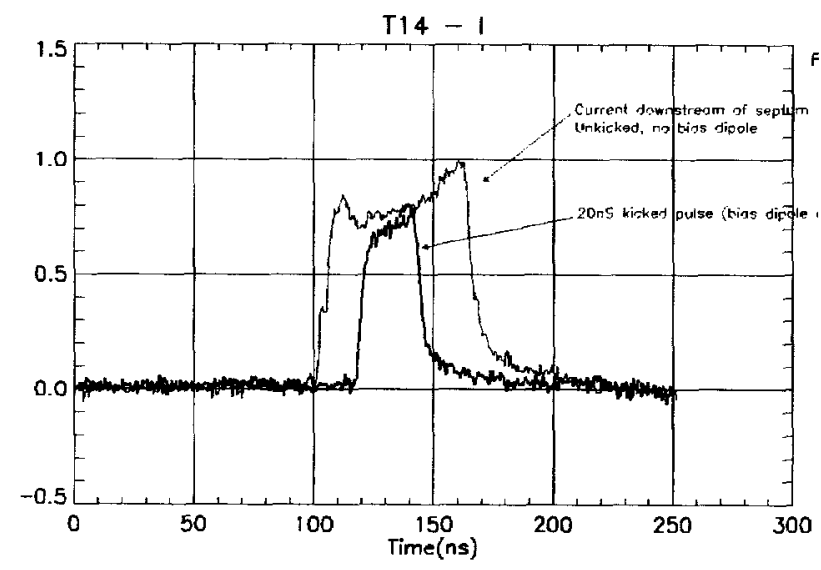

Figure 5 Measured beam current on ETA-II for a full and 20nS-wide kicked beam (100A/div)

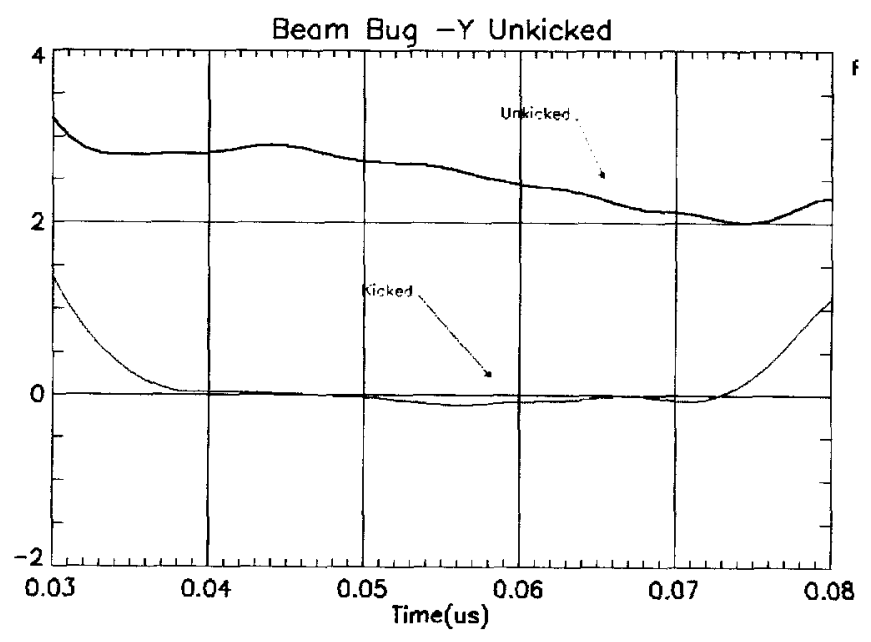

Figure 6 Unkicked and kicked beam position ( $2 \mathrm{~cm} / \mathrm{div})$

\section{References}

[1] Y.J. Chen et al. "Precision fast kickers for kiloampere electron beams" 1999 Particle Accelerator Conference, New York, NY

[2] Ed Cook, et al. "Inductive-adder Kicker Modulator for DARHT 2" Linac2000, Monterey, CA

[3] J. Watson, et al. "A Solid'State Modulator for High Speed Kickers" Particle Accelerator Conference 2001, Chicago, IL

[4] Y.J. Chen "Notes on the Kicker Control System" USPAS 2000W, Tucson, AZ 